\title{
Prior Systemic Chemotherapy for Current
} Cancer

National Cancer Institute

\section{Source}

National Cancer Institute. Prior Systemic Chemotherapy for Current Cancer. NCI

Thesaurus. Code C156796.

An indication that an individual has previously received systemic chemotherapy for their current malignancy. 